\title{
Etika Menyampaikan Informasi Diagnosis Penyakit Terminal kepada Pasien sesuai Konteks Budaya Indonesia
}

\author{
Pukovisa Prawiroharjo ${ }^{\mathrm{I}, 2}$, Putri Dianita Ika Meilia ${ }^{\mathrm{T}, 3}$, Ghina Faradisa Hatta \\ ${ }^{1}$ Majelis Kehormatan Etik Kedokteran Pengurus Besar Ikatan Dokter Indonesia \\ ${ }^{2}$ Departemen Neurologi Fakultas Kedokteran Universitas Indonesia/Rumah Sakit Cipto Mangunkusumo \\ 3Instalasi Kedokteran Forensik dan Pemulasaraan Jenazah, Rumah Sakit Umum Pusat Persahabatan, Jakarta
}

\author{
Kata Kunci \\ Penyampaian berita buruk, diagnosis \\ penyakit terminal, budaya Indonesia \\ Korespondensi \\ pukovisa@ui.ac.id \\ Publikasi \\ (C) $2020 \mathrm{JEKI} / \mathrm{ilmiah} . \mathrm{id}$ \\ DOI \\ I0.26880/jeki.v4ir.4I \\ Tanggal masuk: 20 November 2019 \\ Tanggal ditelaah: II Januari 2020 \\ Tanggal diterima: 1o Februari 2020 \\ Tanggal publikasi: 24 Februari 2020
}

\begin{abstract}
Abstrak Sikap dan perilaku pasien terhadap berita buruk, misalnya diagnosis penyakit terminal ataupun kondisi medis buruk lainnya, harus ditangani secara khusus. Di balik kewajiban dokter untuk bersikap jujur dan mengedepankan autonomy pasien, prinsip etik beneficence dan nonmaleficence menjadi pertimbangan dalam penahanan sebagian atau seluruh informasi yang dapat melemahkan psikis atau fisik pasien. Selain itu, budaya patrilineal dan matrilineal di Indonesia yang masih kental juga mempengaruhi keluarga pasien saat turut serta membuat keputusan atas kondisi medis pasien. Prima facie dalam masalah ini perlu ditinjau dengan mempertimbangkan faktor budaya, kondisi fisik dan psikis pasien, serta Kode Etik Kedokteran Indonesia (KODEKI) yang menjadi pilar dari pertimbangan etik kedokteran di Indonesia.
\end{abstract}

\begin{abstract}
A patient's attitude and behaviour towards bad news, e.g. a diagnosis of terminal disease or other poor medical conditions, should be handled with special attention. While it is the physician's obligation to be honest and prioritise the patient's autonomy, other ethical principles, such as beneficence and non-maleficence, should also be considered in withholding information which could weaken the patient, either psychologically or physically. Furthermore, patrilineal and matrilineal cultures in Indonesia are still strong and family members play an impotant role in making decisions on the patient's behalf. The prima facie in regarding this ethical dilemma needs to be considered from various points of view, such as the patient's cultural background, the physical and physiological state of the patient, as well as the Indonesian medical code of ethics (KODEKI) as the pillar of medical ethics in Indonesia.
\end{abstract}

Indonesia memiliki begitu banyak ragam budaya dan adat istiadat yang sedikit banyak turut mempengaruhi pola interaksi dan komunikasi, termasuk di dalamnya komunikasi kedokteran. Meskipun memiliki budaya dan adat istiadat yang majemuk, para proklamator telah merangkum saripati nilai-nilai yang ada sebagai kesepakatan bangsa, yaitu Pancasila. Musyawarah telah diterima sebagai salah satu unsur penting dari kepribadian Indonesia, yang kemudian dimaktubkan dalam sila keempat Pancasila "Kerakyatan yang dipimpin oleh hikmat kebijaksanaan dalam permusyawaratan/ perwakilan”. Di Indonesia, adalah hal yang lazim jika seorang pasien bermusyawarah bersama keluarga, meskipun di era modern banyak juga pasien yang menginginkan bahwa informasi diberikan oleh dokter hanya kepada dirinya seorang.

Informasi tentang diagnosis penyakit terminal, meskipun disampaikan dengan sangat komunikatif dan santun, tetap akan dicerna sebagai berita buruk dan melahirkan persepsi masa depan pasien yang tidak memungkinkan untuk sembuh sehingga akan menjalani masa sekarat hingga kematian. Di lain sisi, dokter memiliki kewajiban untuk bersikap jujur kepada pasien dan bertindak atas asas manfaat (beneficence) dan tidak membahayakan (non-maleficence) pasien. Hal yang menjadi pertanyaan adalah prima facie dalam konteks tersebut: Apakah tepat sikap dokter untuk 
menahan sebagian atau seluruh informasi tersebut atas asas beneficence dan non-maleficence karena ditakutkan informasi sejenis tersebut sedikit banyak melemahkan daya tahan psikis maupun fisik pasien? Atau apakah lebih tepat untuk memberitahukan sepenuhnya informasi melemahkan tersebut atas asas autonomy pasien? Atas pengaruh budaya dan keluarga pasien, pada praktiknya acapkali dokter menyikapi pemberian informasi tersebut dengan menahannya dari pasien itu sendiri.

\section{Perbedaan Sikap dan Perilaku Pasien serta Keluarganya terhadap Penyampaian Diagnosis Penyakit Terminal}

Beberapa studi menunjukkan perbedaan antara sikap dan perilaku pasien serta keluarganya terhadap pengungkapan diagnosis penyakit terminal. Melalui persepsi pasien, pasien lebih memilih untuk mengetahui diagnosisnya langsung dari dokter sebagai tangan pertama dibandingkan disampaikan oleh keluarganya atau orang lain. Di lain sisi, yakni melalui persepsi keluarga, keluarga lebih memilih untuk menjadi orang pertama yang mengetahui berita buruk tersebut dibandingkan diberitahu langsung kepada pasien terkait. ${ }^{1-6}$ Menurut studi Liu, et al. (2018) di Cina, beberapa faktor signifikan mempengaruhi perbedaan persepsi tersebut, yakni usia, tingkat edukasi, dan tingkat kesejahteraan. Pasien dengan usia yang lebih muda, lebih teredukasi, serta dengan tingkat kesejahteraan yang setara atau lebih tinggi dari rata-rata secara signifikan menuntut haknya untuk mengetahui lebih awal tentang diagnosis penyakitnya. Pasien cenderung memegang prinsip etik autonomy, sedangkan keluarga pasien lebih cenderung berpihak pada prinsip beneficence. ${ }^{1}$

Sejumlah studi meneliti tentang dampak negatif terhadap tingkat kondisi mental, seperti cemas dan depresi, pada kelompok yang diberitahu dan tidak diberitahu perihal diagnosis masing-masing individu. Studi-studi tersebut menunjukkan bahwa tidak ada perbedaan yang signifikan terhadap tingkat cemas maupun depresi pada kedua kelompok. $^{7-9}$ Bahkan beberapa studi dari Iran $^{10}$, India ${ }^{11}$, dan Turki $^{12}$ masing-masing menunjukkan morbiditas psikiatrik dan/atau kualitas hidup yang lebih rendah pada pasien yang tidak tahu tentang prognosisnya yang fatal. Walaupun memang, faktor budaya yang dominan pada kawasan Asia tetap berperan penting dalam penanganan informasi ini. Maka dengan menimbang prinsip etik autonomy dan beneficence terhadap pasien, lebih tepat agar menerapkan cara yang menguatkan hubungan berlandaskan asas kepercayaan dengan juga mempertimbangkan preferensi pasien dalam menerima informasi, terlibat dalam keputusan klinis, serta sejauh apa peran keluarga terhadap dirinya. ${ }^{13}$

\section{Studi Budaya di Asia, Negara Mayoritas Muslim, dan Indonesia}

Pada dasarnya, budaya membentuk pandangan dan kepercayaan pasien, yang mempengaruhi pandangan terhadap penyakit, penderitaan, kematian, kecenderungan dalam membuat keputusan, menerima berita buruk, dan asuhan akhir hayat. Bentuk perbedaan budaya ini dapat dilihat antara negara-negara Barat dengan Timur, termasuk negara di mana mayoritas penduduknya adalah muslim. ${ }^{14} \mathrm{Di}$ negara barat, terlebih Amerika Serikat ${ }^{15,16}$, Inggris $^{17}$, Kanada ${ }^{18}$, dan Finlandia ${ }^{19}$, prinsip etik autonomy lebih dipegang erat sehingga lebih menekankan pengungkapan yang jujur terkait prognosis dan diagnosis terminal kepada pasien terlebih dahulu. Hanya pasien yang berhak menentukan kepada siapa informasi tersebut akan diungkapkan.

Sementara itu, negara-negara di Timur lebih memegang budaya patriarki yang mengusung hierarki dalam pembuatan keputusan sehingga keputusan tidak sepenuhnya berada di tangan pasien, melainkan pada keluarga. Budaya tersebut dapat dilihat pada negara-negara di Asia, seperti Jepang ${ }^{8,19}$, dan negara-negara mayoritas muslim, seperti Turki ${ }^{20}$, Lebanon ${ }^{21}$, Kuwait $^{22}$, dan Saudi Arabia ${ }^{23}$. Memang budaya kolektif umum untuk dijumpai pada sejumlah negara Asia dan negara mayoritas muslim. Hal ini menyebabkan pendekatan yang cenderung memegang prinsip bahwa penyakit seseorang adalah masalah keluarga sehingga tak masalah jika keluarga menutupi kebenarannya demi 
"kebaikan" pasien. Terdapat kekhawatiran bahwa apabila kebenaran diberitahukan kepada pasien maka harapan pasien akan sirna, yang berujung pada keputusasaan, kesengsaraan fisik, kelelahan mental, dan mempercepat kematian. Persepsi dalam budaya Etiopia menunjukkan bahwa pasien bahkan ditakutkan mungkin untuk meninggal akibat syok terhadap berita buruk. Di beberapa negara Eropa selatan dan timur, serta sejumlah negara di Asia dan Timur Tengah, dipersepsikan bahwa tidak memberikan informasi medis yang buruk atau terminal lebih manusiawi dan etis. Lagi-lagi, prinsip beneficence terhadap pasien lah yang melandasi perilaku dan persepsi tersebut. ${ }^{14}$

Walaupun penting untuk menghormati perbedaan kepercayaan kebudayaan pasien, prinsip etik autonomy dan justice yang merupakan hak dasar setiap pasien tidak boleh diabaikan. Hal ini dapat berujung pada pengobatan yang "sia-sia" dalam sistem perawatan yang memiliki keterbatasan sumber daya karena pada dasarnya asuhan medis perlu untuk menjunjung prinsip patient-centred care. Perlu diingat bahwa tetap penting untuk mempertimbangkan preferensi pasien terlebih dahulu dalam penerimaan informasi tersebut. ${ }^{13}$

\section{Ketentuan Umum KODEKI tentang Penyampaian Diagnosis Penyakit Terminal}

Penyampaian diagnosis penyakit terminal terkandung dalam pasal 5 KODEKI, yang menyatakan bahwa, "Tiap perbuatan atau nasihat dokter yang mungkin melemahkan daya tahan psikis maupun fisik, wajib memperoleh persetujuan pasien/keluarganya dan hanya diberikan untuk kepentingan dan kebaikan pasien tersebut." Pada cakupan pasal 5 poin 3 dinyatakan, "Dalam rangka menimbulkan dan/atau menjaga rasa percaya diri pasien, dokter seyogyanya dilarang berbohong kepada pasiennya yang menderita penyakit berat/parah, kecacatan atau gangguan kualitas hidup, tetapi boleh menahan sebagian informasi yang dapat melemahkan psikis pasien dan/atau fisiknya." Sementara pasal 5 poin 4 menyatakan "Dokter wajib menghormati keinginan pasien yang menolak untuk mendapat informasi mengenai penyakitnya sendiri atau tindakan/pengobatan yang memperlemah fisik dan mentalnya, namun seyogyanya dilakukan setelah memperoleh ijin pasien dan menjelaskan informasi tersebut kepada keluarga pasien." ${ }^{24}$

Penjelasan pasal 5 KODEKI menyatakan, "Pada diri pasien sebagai manusia, kaitan badan/tubuh dan jiwa/mental tidak dapat dipisahkan satu sama lain. Melemahkan daya tahan psikis dan fisik adalah bertentangan dengan fitrah/tugas ilmu kedokteran, karena hal ini jika dibiarkan justru akan membahayakan nyawa atau memperberat penderitaannya." Selanjutnya, "Pasien yang memiliki otonomi namun akan terpapar risiko fisik dan mental akibat perjalanan penyakitnya sendiri maupun tindakan/obat yang akan diberikan dokter, khususnya yang diramalkan berat (fatal), serius, berpotensi kecacatan atau akan merugikan, wajib diberi informasi memadai sebelumnya. Kecuali bila pasien tersebut tidak mampu mengerti dan/atau memahami atau terdapat gangguan kapasitas otonominya sehingga dirinya tidak mampu membuat keputusan menentukan (yang terbaik) baginya. Namun dalam budaya Indonesia, pasien sering ditemani oleh suami/ istri atau bapak/ibu atau anak-anaknya, sehingga pemberian informasi dilakukan bersamaan kepada mereka, apalagi kategori perawatan akhir kehidupan. Kecuali yang amat khusus privasinya, pemberian informasi bersamaan ini perlu dimintakan persetujuan pasien lebih dulu." 24

Pada narasi yang ada di pasal 5 KODEKI sebenarnya menyatakan, “...wajib memperoleh persetujuan pasien/ keluarganya dan hanya diberikan untuk kepentingan dan kebaikan pasien tersebut." 24 Kami setuju dengan narasi KODEKI tersebut dengan fleksibiltas penafsiran bahwa persetujuan dapat diajukan kepada pasien atau keluarganya. Kata "atau" di sini semestinya membuat fleksibel dalam teknis pelaksanaannya, yaitu apakah persetujuan tersebut diajukan kepada pasien terlebih dahulu, kepada keluarganya terlebih dahulu, ataukah secara bersamaan. Namun, sayangnya pada cakupan dan penjelasan pasal 5 KODEKI ini belum memberikan tempat pada sikap yang jamak ada pada budaya negara Asia dan mayoritas muslim, yaitu memberikan informasi 
terkait kepada keluarga pasien terlebih dahulu baru kemudian pasien. Meskipun pada uraian penjelasan pasal, disebutkan bahwa pemberian informasi dilakukan bersamaan waktunya kepada pasien dan kepada keluarga dalam mempertimbangkan kondisi yang ada di Indonesia di mana pasien sering ditemani keluarganya. Ke depannya, diperlukan revisi terhadap cakupan dan penjelasan pasal 5 KODEKI ini untuk mengakomodasi hal yang jamak dilakukan di Indonesia sebagai budaya bahwa sikap memberikan informasi kepada keluarga pasien terlebih dahulu dapat dibenarkan dengan memperhatikan ketentuanketentuan tertentu.

\section{Kode Etik Negara Lain tentang Penyampaian Informasi Diagnosis Penyakit Terminal}

Di Amerika Serikat, American Medical Association (AMA) mengatur masalah penyampaian informasi dalam konteks informed consent, komunikasi, dan pembuatan keputusan. Klinisi harus jujur dalam menyampaikan kondisi medis pasien secara langsung atau secepatnya. Menahan sebagian informasi dapat dilakukan hanya dengan persetujuan dan kemauan pasien atau pada keadaan pasien tidak dapat memiliki kemampuan pengertian penuh atas informasi tersebut. Dalam menahan informasi, klinisi memiliki andil untuk mengatur jumlah pemberitahuan informasi yang dibutuhkan sedikit demi sedikit, tergantung pada kondisi kesiapan pasien. Klinisi juga dapat berkonsultasi kepada keluarga pasien atau pun komite etik untuk memutuskan keuntungan dan kerugian relatif atas penahanan informasi tersebut. Pada dasarnya, asas etik autonomy dan beneficence tetap diperhitungkan. ${ }^{25}$

Bolehkah Dokter Menyampaikan Informasi Diagnosis Penyakit Terminal kepada Keluarga Pasien saja tanpa Pasien Tersebut Diberitahu?

Bagian cakupan pasal maupun penjelasan pasal 5 KODEKI menerangkan bahwa sikap dokter memberitahu keluarganya terlebih dahulu dan tidak memberitahu kepada pasien belum dapat diterima sebagai salah satu alternatif, kecuali jika pasien telah jelas menolak diberitahu informasi tersebut dan mempersilakan diberikan kepada keluarga sesuai cakupan pasal 5 poin $4 .{ }^{24}$ Sebaliknya, jika pasien berkeberatan karena informasi tersebut dianggap sangat pribadi, maka informasi tersebut hanya dapat diteruskan kepada keluarganya atau pihak lain atas persetujuan pasien lebih dulu. Meskipun pada penjelasan pasal, disebutkan juga mengenai pemberian informasi kepada pasien dan keluarga dalam waktu bersamaan dengan mempertimbangkan kondisi di Indonesia bahwa pasien sering ditemani keluarganya ketika berobat. Sebagaimana diuraikan sebelumnya, kami menyarankan agar melengkapi cakupan dan penjelasan pasal 5 KODEKI dengan turut memasukkan bahwa penyampaian informasi kepada keluarga terlebih dahulu dapat dibenarkan sebagai sikap alternatif sesuai konteks dan kondisi yang ada.

Banyak dokter di Indonesia lebih nyaman memberitahukan informasi penyakit terminal ini ke keluarga terdekat terlebih dahulu dengan maksud agar keluarga dapat mengatasi kesedihannya, lalu kemudian dapat menguatkan mental pasien. Namun, yang perlu disadari oleh dokter Indonesia bahwa bisa terdapat potensi masalah yang perlu diantisipasi apabila informasi diberikan kepada keluarga pasien terlebih dahulu. Bahkan pada konteks tertentu, kebijakan ini dapat pula menjadi gelagat kurang baik saat pasien yang semestinya tahu atas kondisinya, merasa aneh melihat keluarganya tampak bersedih hati sementara pasien tidak mengetahui apa-apa. Alih-alih tujuan mulia tersebut tercapai, hal ini justru dapat memicu konflik kecil antara pasien dan keluarganya karena pasien dapat saja menaruh curiga.

Hal lain yang dapat terjadi adalah apabila dokter sengaja tidak memberitahukan kepada pasien perihal masalah kesehatan yang sebenarnya. Jika kemudian keluarga pasien juga berembuk di antara mereka sendiri dan memutuskan pasien tidak perlu diberitahu hingga akhir hidupnya, keputusan untuk membiarkan pasien sekarat dan wafat dalam kondisi tidak mengetahui kebenaran prognosis medisnya sejak awal adalah tindakan yang tidak etis. Dapat dibayangkan bahwa detil kehidupan pasien tidak seluruhnya diketahui keluarga, misalnya pasien dapat memiliki hutang-piutang 
dan janji yang belum ditepati kepada orang lain. Seandainya informasi prognosis terkait penyakit terminal ini diketahui oleh pasien sedini mungkin, maka setidaknya pasien dapat melakukan perencanaan-perencanaan strategis dalam akhir hidupnya agar nanti saat meninggal dunia, ia sudah bebas dari hutang, janji yang belum ditepati, dapat menulis wasiat, dapat mengukir karya terakhir, dan sebagainya.

Capaian ini jelas bertolak belakang dengan apa yang pasien ikhtiarkan, yaitu hampir setiap hari bersedia penuh semangat antri panjang mengular di rumah sakit demi menjaga harapan ia akan sembuh di kemudian hari. Di satu sisi, bisa jadi dokter dan keluarga melihat hal ini sebagai aspek positif. Namun harus diakui, di sisi lain hal ini dapat ditafsirkan sebaliknya menjadi sangat negatif. Apabila kita sepakat bahwa kondisi meninggal dunia tanpa hutang, telah lunas semua janji bakti, dan sempat mengukir karya terakhir adalah bentuk yang lebih agung dibandingkan memelihara semangat berobat hari ke hari, maka misinformasi yang dialami pasien justru menjauhkan pasien dari peluang dapat meraih kondisi meninggal dunia yang sangat baik dan memelihara kehormatan dirinya.

\section{Informasi Apa yang Dapat Ditahan Sebagian oleh Dokter tanpa Mengurangi Kejujuran?}

Pada cakupan pasal 5 KODEKI 2012, disebutkan bahwa dalam rangka menimbulkan dan/atau menjaga rasa percaya diri pasien, dokter seyogyanya dilarang berbohong kepada pasiennya yang menderita penyakit berat/parah, kecacatan atau gangguan kualitas hidup tetapi boleh menahan sebagian informasi yang dapat melemahkan psikis pasien dan/atau fisiknya. ${ }^{24}$ Informasi yang melemahkan tersebut di dalamnya termasuk informasi mengenai rincian prognosis, progresivitas, komplikasi penyakit, proses penyakit dalam mengakibatkan kematian, hingga perkiraan kemungkinan sisa waktu hidup. Hal ini juga sejalan dengan pendapat AMA. Walaupun Amerika Serikat merupakan negara yang sangat menjunjung hak autonomy pasien, penahanan informasi dapat dirancang sedemikian rupa sesuai dengan kebutuhan dan kondisi kesiapan pasien, yang dapat dinilai oleh klinisi penanggung jawab pelayanan pasienyang tentunya juga atas persetujuan pasien. ${ }^{25}$ Akan tetapi, perlu digarisbawahi pernyataan atas persetujuan pasien. Informasi merupakan alat yang ampuh, baik untuk bahaya maupun kebaikan, sehingga menahan informasi dari pasien yang kompeten dapat menyebabkan pasien tidak berdaya dan pembenarannya demi kesejahteraan dapat dipertanyakan. Menahan informasi dari pasien yang kompeten tidak memberikan dampak menguntungkan dalam jangka panjangnya, terutama dalam hal pembuatan keputusan ke depannya. ${ }^{26}$

\section{Rekomendasi Mekanisme Pemberitahuan Informasi Pasien dengan Penyakit Terminal Sesuai Budaya Indonesia}

Indonesia masih kental dengan kebudayaan patrilineal maupun matrilineal. Kedua budaya ini memiliki andil dalam pengambilan keputusan masyarakat secara umum. ${ }^{27,28}$ Sebelumnya, perlu diingat makna kekerabatan yang melekat pada budaya ini, yakni hubungan kekeluargaan seseorang dengan orang lain yang memiliki hubungan darah atau keturunan dalam satu keluarga.

Mempertimbangkan budaya Indonesia yang masih kental asas patrilineal dan matrilineal di berbagai daerah dan besar pengaruhnya pada pembuatan keputusan seorang individu, kami mengusulkan bahwa dapat saja keluarga diberitahu terlebih dahulu, namun dalam waktu tidak lama (misalnya dalam sepekan), pasien kemudian diberitahu. Informasi yang disampaikan sebaiknya juga tidak sekedar terkait aspek medis saja, namun juga nasihat humanis menyentuh kalbu pasien tentang hakikat kehidupan dan kematian. Dalam upaya luhur ini, kerjasama dengan pemuka agama, psikolog/psikiater, dan tokoh masyarakat menjadi penting dilakukan oleh dokter maupun difasilitasi oleh rumah sakit.

Terlepas dari kekentalan budaya yang mempengaruhi pembuatan keputusan pada masyarakat luas di Indonesia, edukasi yang mendalam terhadap persepsi autonomy pasien tetap perlu dilakukan. Menimbang dampak jangka panjang yang lebih signifikan, pendirian masyarakat terhadap hak autonomy atas 
hidup dan matinya perlu dikuatkan, yakni merupakan hak pasien untuk mengetahui secara penuh informasi atas kondisi medisnya, atau sebaliknya juga merupakan hak pasien untuk acuh atas informasi yang dapat diberikan dan menyerahkan keputusan pada keluarga-sesuai budaya yang berlaku. Kembali lagi pada peran penting dokter agar dapat cermat dalam mengamati pasien yang dirawatnya untuk menilai kesiapan fisik dan mental pasien dalam menerima informasi yang berpotensi melemahkan dirinya tersebut.

\section{KESIMPULAN}

Penyampaian diagnosis penyakit terminal melibatkan prinsip etik autonomy, beneficence, serta non-maleficence, dengan mempertimbangkan faktor budaya patrilineal dan matrilineal di Indonesia yang dapat mempengaruhi pembuatan keputusan seorang pasien. Edukasi yang mendalam tentang persepsi hak autonomy atas hidup dan matinya juga tetap perlu dilakukan dan dikuatkan.

\section{KONFLIK KEPENTINGAN}

Penulis tidak memiliki konflik kepentingan dalam penulisan artikel ini.

\section{REFERENSI}

1. Liu Y, Yang J, Huo D, Fan H, Gao Y. Disclosure of cancer diagnosis in China: the incidence, patients' situation, and different preferences between patients and their family members and related influence factors. Cancer Manag Res. 2018;10:21732181. Published 2018 Jul 23. doi:10.2147/ CMAR.S166437

2. Chittem M, Norman P, Harris PR. Relationships between perceived diagnostic disclosure, patient characteristics, psychological distress and illness perceptions in Indian cancer patients. Psychooncology. 2013;22(6):1375-1380.
3. Wang SY, Chen CH, Chen YS, Huang HL. The attitude toward truth telling of cancer in Taiwan. J Psychosom Res. 2004;57(1):5358.

4. Jotkowitz A, Glick S, Gesundheit B. Truth-telling in a culturally diverse world. Cancer Invest. 2006;24:786789. [PubMed] [Google Scholar]

5. Jotkowitz AB, Glick S, Porath A. A physician charter on medical professionalism: A challenge for medical education. Eur J Intern Med. 2004;15:5-9. [PubMed] [Google Scholar]

6. Hallenbeck J, Arnold R. A request for non-disclosure: Don't tell mother. J Clin Oncol. 2007;25:50305034. [PubMed] [Google Scholar]3

7. Montazeri A, Tavoli A, Mohagheghi MA, Roshan R, Tavoli Z. Disclosure of cancer diagnosis and quality of life in cancer patients: should it be the same everywhere? BMC Cancer. 2009;9:39.

8. Maeda Y, Hagihara A, Kobori E, Nakayama T. Psychological process from hospitalization to death among uninformed terminal liver cancer patients in Japan. BMC Palliat Care. 2006;5:6.

9. Qian H, Hou L. Psychological impact of revealing a diagnosis of lung cancer to patients in China. J Thorac Dis. 2016;8(10):2879-2884.

10. Montazeri A, Tavoli A, Ali M, et al. Disclosure of cancer diagnosis and quality of life in cancer patients: should it be the same everywhere? BMC Cancer. 2009; 9:39.

11. Alexander PJ, Dinesh N, Vidyasagar MS. Psychiatric morbidity among cancer patients and its relationship with awareness of illness and expectations about treatment outcome. Acta Oncol. 1993;32:623-6.

12. Atesci F, Baltalarli B, Oguzhanoglu N, et al. Psychiatric morbidity among cancer patients and awareness of illness. Support Care Cancer. 2004; 12: 161-7. 
13. O'Kelly CDP, Urch C, Brown EA. The impact of culture and religion on truth telling at the end of life. Nephrology Dialysis Transplantation. 2011;26(12):3838-42. https://doi.org/10.1093/ndt/gfr630

14. Kazdaglis GA, Arnaoutoglou C, Karypidis D, Memekidou D, Spanos G, Papadopoulos $\mathrm{O}$. Disclosing the truth to terminal cancer patients: a discussion of ethical and cultural issues. EMHJ. 2010;16(4):442-7.

15. McCabe MS, Wood WA, Goldberg RM. When the family requests withholding the diagnosis: who owns the truth?. J Oncol Pract. 2010;6(2):94-96. doi:10.1200/ JOP.091086

16. Seale C. Communication and awareness about death: a study of a random sample of dying people. Social science and medicine, 1991, 32(8):943-52.

17. Hebert PC et al. Bioethics for clinicians: 7.Truth telling. Canadian Medical Association journal, 1997, 156(2):225-8.

18. Sainio C, Lauris S, Eriksson E. Cancer patients' views and experiences of participation in care and decision making. Nursing ethics, 2001, 8(2):97-113.

19. Tanida N. Japanese attitudes towards truth disclosure in c ancer. Scandinavian journal of social medicine, 1994, .7-50:)1(22

20. Bozcuk $\mathrm{H}$ et al. Does awareness of diagnosis make any differ- ence to quality of life? Determinants of emotional functioning in a group of cancer patients in Turkey. Supportive care in can-cer, 2002, 10(1):517.

21. Hamadeh GN, Adib SM. Cancer truth disclosure by Lebanese doctors. Social science \& medicine, 1998, 47(9):1289-94.

22. Qasem AA et al. Disclosure of cancer diagnosis and prognosis by physicians in Kuwait. International journal of clinical practice, .8-215:)3(56,2002
23. Mobeireek AF et al. Communication with the seriously ill: physicians' attitudes in Saudi Arabia. Journal of medical ethics, .5-282:)5(22,1996

24. Purwadianto A, Soetedjo, Gunawan S, Budiningsih Y, Prawiroharjo P, et al. Kode etik kedokteran Indonesia. Jakarta: Pengurus Besar Ikatan Dokter Indonesia; 2012.

25. American Medical Association. Code of medical ethics: consent, communication $\&$ decision making. Dapat diakses: https://www.ama-assn.org/deliveringcare/ethics/code-medical-ethics-consentcommunication-decision-making

26. Edwin A. Don't Lie but Don't Tell the Whole Truth: The Therapeutic Privilege - Is it Ever Justified?. Ghana Med J. 2008;42(4):156161. 